\title{
RUSSIAN INDUSTRY IN NOVEMBER 2013
}

\author{
S.Tsukhlo
}

A detailed analysis of the system of indices of business surveys of the Gaidar Institute ${ }^{1}$ showed that in November the Russian industry made an attempt to break away from stagnation. However, higher intensity of growth in production and optimism of output plans is supported so far by the estimates of stocks of finished products, rather than the demand. Utilization of the pricing factor for promotion of the demand is restrained by intense growth in costs at the end of the year.

\section{Demand on Industrial Produce}

In November, the dynamics of demand on industrial produce did not undergo principal changes as compared to October as regards either the initial data or that cleared of a seasonal factor (Fig. 1). As a result, from the beginning of the second half-year growth rates of reduction of sales (after clearing of the seasonal factor) remain within the limits of -9 points...-6 points and is somewhat better than the result of respective months of the previous year. But the demand keeps falling. The above factor forms quite a large share of "below the norm" answers which yields just a little to the share of positive estimates of sales in the $4^{\text {th }}$ quarter of 2013. Forecasts of sales have been losing optimism during all the months of 2013 (except for May) and fell in November to -17 points though in January surged up to +28 points. Formal methods of clearing of the seasonal factor bring the results of expectations of the past few months in the positive area, though that result is rather small and unstable one and prone to a downward trend.

\section{Stocks of Finished Products}

Evaluations of stocks of finished products in the past few months form a positive impact on the output of the Russian industry (Fig. 2). After a surge in June to +21 points, the index fell to +6 points by November; it is to be noted that the main losses related to redundancy took place in November. However growth in output due to the effect of estimates of stocks alone without adequate changes in the dynamics of the demand creates a basis for the next growth in their balance and subsequent slowdown of production.

\footnotetext{
1 Surveys of managers of industrial enterprises are carried out by the Gaidar Institute in accordance with the European harmonized methods on a monthly basis from September 1992 and cover the entire territory of the Russian Federation. The size of the panel includes about 1,100 enterprises with workforce exceeding $15 \%$ of workers employed in industry. The panel is shifted towards large enterprises by each sub-industry. The return of queries amounts to $65-70 \%$.
}

SOLVENT DEMAND CHANGES CLEARED OF A SEASONAL FACTOR (BALANCE=\%GROWTH-\%DECREASE)

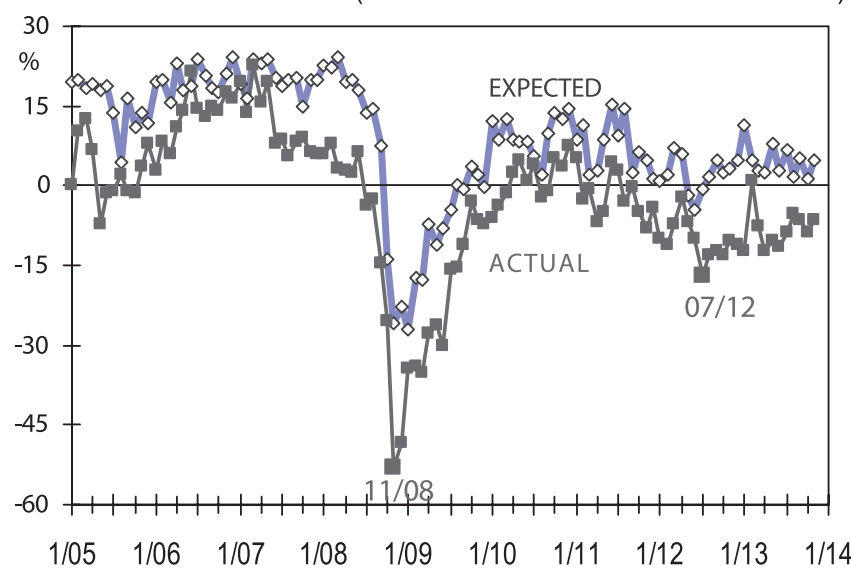

Fig. 1

BALANCE OF EVALUATIONS OF STOCKS OF FINISHED PRODUCTS (BALANCE $=$ $=\% A B O V E$ THE NORM $-\% B E L O W$ THE NORM)

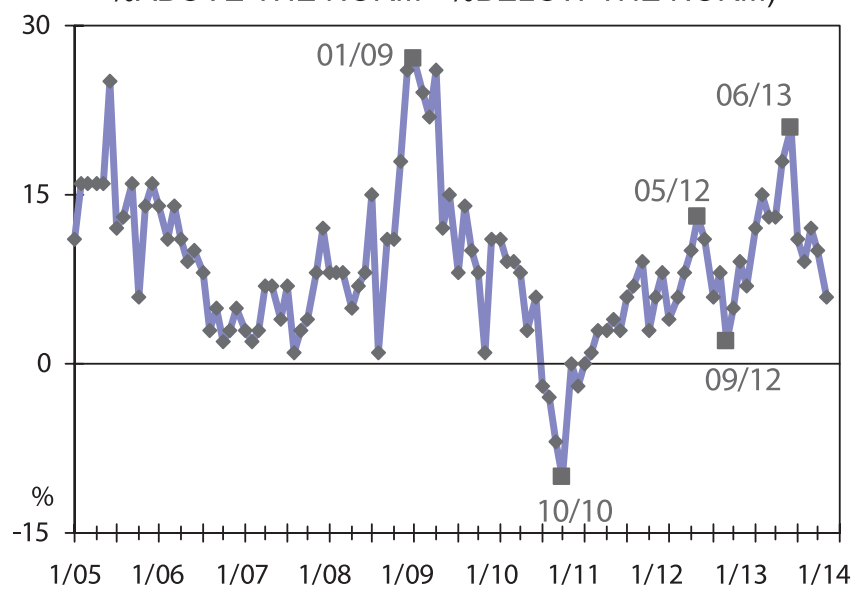

Fig. 2 


\section{The Output}

In November, the surveys' data on the dynamic$s$ of industrial output volumes showed some positive changes in the index (Fig. 3). The initial balance (growth rates) rose by 2 points, while that cleared of a seasonal factor, by 3 points. Such a positive change in the surveys' data may result in a break of the extended stagnation of industrial production for at least one month as it is not supported so far by similar trends in the dynamics of sales.

\section{Prices of Enterprises}

In November, the industry preserved a zero balance (growth) of actual price changes. So, for the two month running, enterprises' selling prices by the entire sector do not change (Fig. 4). However, by various industries the situation differs a great deal. According to surveys, the most dramatic drop in prices is observed in the nonferrous industry where the balance of October-November amounts to -20 points. Similar changes - though of a smaller extent - are observed in the building materials industry (-10 points), too. In the ferrous industry, chemical industry, engineering and forest industry, there are zero balances, that is, prices are stable. In the first two months of the $4^{\text {th }} x$ quarter, growth in selling prices was registered only in the forest industry ( +9 points) and the food industry (+31 points).

\section{Enterprises' Costs}

Such a pricing policy contributes to actual and future worsening of the financial situation of the industry. Such a conclusion is prompted by the data on the dynamics of costs. According to the data of the surveys, in the $4^{\text {th }}$ quarter of 2013 the cost of production showed the most intense growth in the past 11 quarters. The balance (the intensity of growth) of the index amounted to +30 points, though in the $2^{\text {nd }}$ quarter it fell to +5 points which was the historic minimum. In the $3^{\text {rd }}$ quarter of 2013 (that is, after a planned inflation surge early in the $2^{\text {nd }}$ half year), it rose only to +20 points. Also, the result of the $4^{\text {th }}$ quarter of 2013 surpassed a surge of costs early in the year when the balance of changes rose only to +24 points. But, at present, there can be no "planned" reasons for growth in prices on primary products and materials...

\section{Actual Dynamics and Lay-Off Plans}

In autumn 2013, the dynamics of employment demonstrated definitely a more positive situation than in the previous months and respective months of 2012 (Fig. 5). In September-November, the average balance (the rate of change) amounted to -5 points, while in the first eight months the value of the index
CHANGES IN OUTPUT VOLUMES CLEARED OF

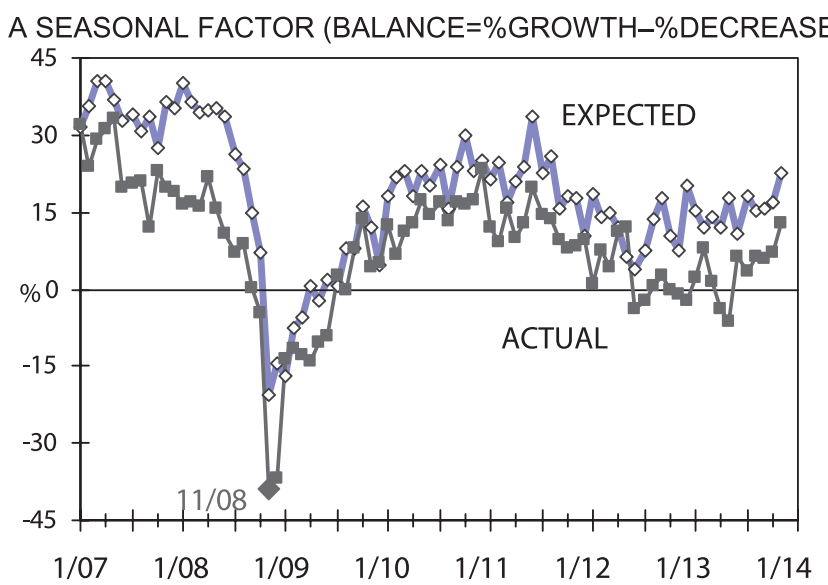

Fig. 3

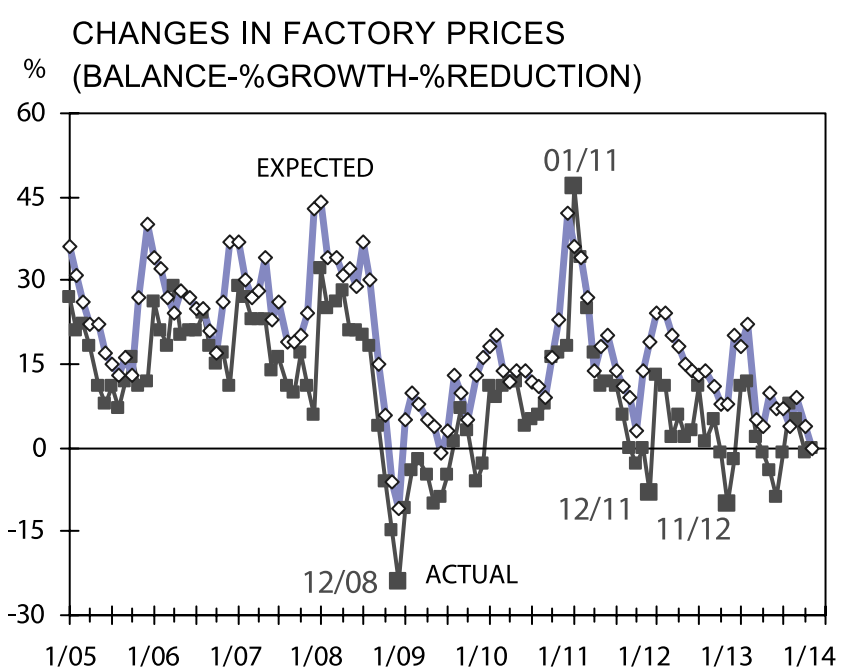

Fig. 4

CHANGES IN EMPLOYMENT

(BALANCE $=\%$ GROWTH-\%DECREASE)

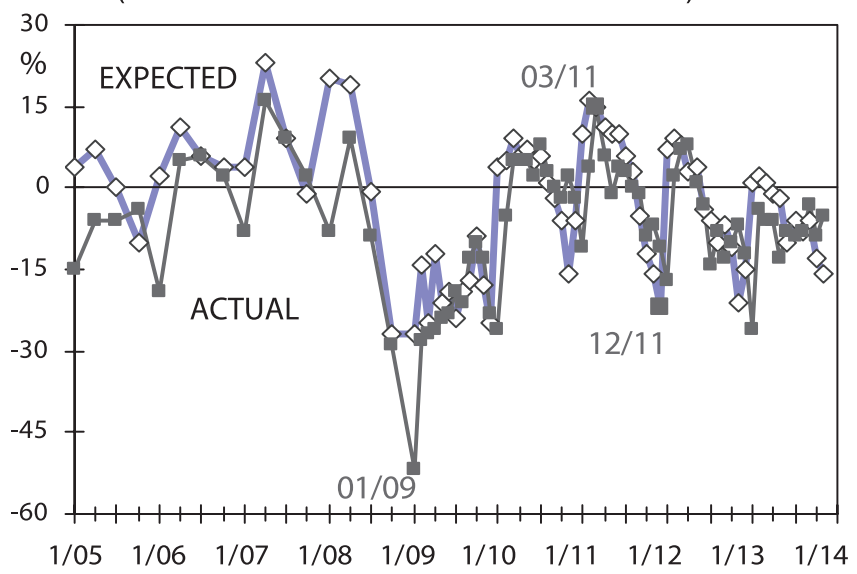

Fig. 5 
was equal to -10 points. The extent of intensity of layoffs of workers at industrial enterprises seems to be going downwards, but reduction of those employed in industry continues. Plans of a change in the number of workers are becoming not that gloomy as a year before. For two months running, they stabilized at the level of -15 points, that is, the extent of lay-offs is expected to be higher than that of hiring.

\section{Enterprises' Investment Plans}

The Russian industry is still unprepared to invest in its own production. For four months running, the balance of investment plans of enterprises is in the negative zone at the level of the post-crisis minimum (Fig. 6). Intentions to scale down investments are still higher than those to increase them. But in November 2013, there was another negative result. For the first time since the beginning of 2010, the share of the "will decrease" answers became equal to that of the "will not change" answers». If stagnation expands in the Russian industry a little more, there will be absolute prevalence of enterprises which scale down investments in their own production.

\section{Lending to Industry}

Conditions of lending to industry have remained on the same level for over three years. The aggregate availability of loans is within the limits of $69-75 \%$ on average in the industry in general from May 2010.
EXPECTED CHANGES IN INVESTMENTS IN CAPITAL ASSETS AGAINST THE PREVIOUS YEAR

(BALANCE=\%GROWTH-\%DECREASE)

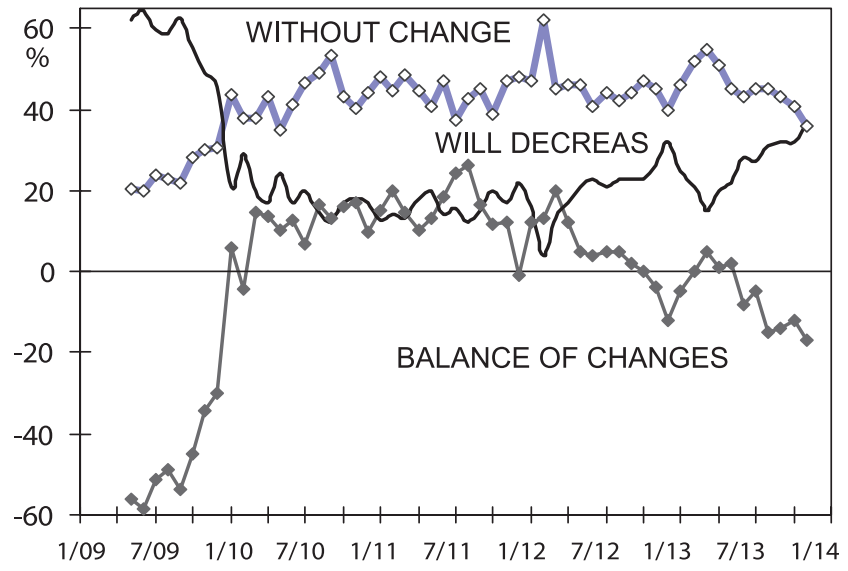

Fig. 6

However, within that period the rate offered by banks on ruble loans fell from $15 \%$ per annum to $11.8 \%$ against October 2011 and then rose to $13.1 \%$ by February 2013 and fell again to $12.4 \%$ by November 2013. In the $4^{\text {th }}$ quarter of 2013 , the lowest interest rates were offered by banks to the iron and steel industry and the chemical industry (11\%), engineering $(12.1 \%)$ and food industry (12.7\%), while the highest interest rates $(13.9 \%)$ were offered to the building industry and the light industry. 